\title{
Polarized XRF Spectrometer with a 40-mW X-Ray Tube
}

\author{
*Ryohei Tanaka', Tomohiro Sugino', Daisuke Yamashita', Naomi Shimura², \\ and Jun Kawai'
}

'Department of Materials Science and Engineering, Kyoto University, Sakyo-ku, Kyoto 606-8501, Japan ${ }^{2}$ RES-Lab Co., Ltd., Kyokuto Electric Bldg., 6-2-1 Shinmori, Asahi-ku, Osaka 532-0022, Japan

${ }^{*}$ Corresponding author: Ryohei Tanaka, E-mail: tanaka.ryohei.5r@kyoto-u.ac.jp

Submitted 30 March 2018, received in revised form 08 June 2018

\begin{abstract}
A three-dimensional polarized X-ray fluorescence (XRF) spectrometer was assembled with a lowpower X-ray tube of 40 milliwatts, and a sample of stainless steel was measured with an acrylic polarizer. Based on the Schrödinger's wave picture of Compton scattering, the dependence of the de Broglie wavelength and the scattering angle of a recoil electron on the incident $X$-ray energy were calculated. When the incident X-rays were scattered at an angle of $90^{\circ}$, the de Broglie of the recoil electron always went away at an angle of $45^{\circ}$ with the incident X-rays and the de Broglie wavelength varied for any wavelength of the incident X-rays, i.e. we could select the scattering angle of the recoil electron to be $45^{\circ}$ according to the incident X-ray energy and it could then be regarded as $45^{\circ}$ Bragg diffraction that could produce highly polarized X-rays. The polarization measurement of scattered X-rays from an acrylic and lead plates substantiated that Compton scattered X-rays from the acrylic plate had higher degree of polarization than the elastically scattered X-rays from the lead plate. Highly polarized Compton scattered X-rays from the light-element polarizer led to the background reduction and the changes of the characteristic X-ray intensity in XRF spectra measured by our laboratory-made spectrometer.

Key words: polarized X-ray fluorescence spectrometer, stainless steel, acrylic polarizer, Compton scattering, background.
\end{abstract}

\section{Рентгенофлуоресцентный спектрометр с поляризатором и 40 мВт рентгеновской трубкой}

\author{
${ }^{\star}$ Ryohei Tanaka1, Tomohiro Sugino1, Daisuke Yamashita1, Naomi Shimura², \\ and Jun Kawai'
}

${ }^{1}$ Department of Materials Science and Engineering, Kyoto University, Japan, Kyoto 606-8501, Sakyo-ku ${ }^{2}$ RES-Lab Co., Ltd., Kyokuto Electric Bldg.,Japan, Osaka 532-0022, Asahi-ku, 6-2-1 Shinmori

*Адрес для переписки: Ryohei Tanaka, E-mail: tanaka.ryohei.5r@kyoto-u.ac.jp

Поступила в редакцию 30 марта 2018 г., после исправления - 8 июня 2018 г.

\begin{abstract}
Трехмерный рентгеновский флуоресцентный спектрометр с поляризатором (РФА) был собран с использованием маломощной рентгеновской трубки. Размер спектрометра составлял 25 см в длину, ширина и высота по 10 см. Расстояние от рентгеновской трубки до поляризатора составляло 10 мм, между образцом и детектором - 10 мм. Камера образцов не вакуумировалась. Образец устанавливали на дно акрилового блока. Рентгеновское излучение падало на поляризатор под углом $45^{\circ}$, и после отражения направлялось на образец под углом в $45^{\circ}$. Использовали рентгеновскую трубку с вольфрамовым анодом фирмы Moxtek (номинальная мощность 4 Вт, максимальное напряжение 50 кВ). В качестве поляризатора использовали акриловую $\left(\mathrm{C}_{5} \mathrm{H}_{2} \mathrm{O}_{8}\right)_{n}$ пластину площадью 80 мм $^{2}$ и толщиной 30 мм. Излучение регистрировали детектором SDD (RES-Lab, Osaka) площадью 100 мм² $^{2}$, толщина кремниевого кристалла составляла 450 мкм. Толщина бериллиевого окна - 8 мкм. Холодильник Пельтье понижал температуру детектора до -30 С. Образец из нержавеющей стали измеряли с акриловым поляризатором. На основе волновой теории Шредингера комптоновского рассеяния рассчитана зависимость длины волны де Бройля и угла рассеяния электрона отдачи в
\end{abstract}


зависимости от энергии падающего рентгеновского излучения. Измерение поляризации рассеянного рентгеновского излучения подтвердило, что некогерентно рассеянное на акриловой пластинке рентгеновское излучение имело более высокую степень поляризации, чем когерентно рассеянное рентгеновское излучение от свинцовой пластины. Высокополяризованное некогерентно рассеянное рентгеновское излучение от поляризатора из элемента с малым атомным номером привело к уменьшению фона и изменению интенсивности характеристического рентгеновского излучения в РФА спектрах, измеренных нашим лабораторным спектрометром.

Ключевые слова: рентгенофлуоресцентный спектрометр, поляризация излучения, акриловый поляризатор, комптоновское рассеяние, фрон, нержавеющая сталь.

\section{INTRODUCTION}

Polarized X-rays are produced by (i) Bragg diffraction, (ii) Barkla scattering, or (iii) the use of a secondary target [1]. When X-rays impinge on a Bragg crystal at an angle of $45^{\circ}$, only $\sigma$-polarization that is parallel to the crystal surface is diffracted, which leads to the perfect linear polarization. This is the Bragg diffraction method. When X-rays are scattered to a right angle $\left(90^{\circ}\right)$ with the incident direction, they are also polarized, which is called Barkla scattering [2]. When primary X-rays from an X-ray source fall on a secondary target, fluorescent $X$-rays are emitted from the target. The use of the secondary target with the polarized geometry is considered to be able to achieve the background reduction in XRF spectra [3].

The XRF analysis employing polarized X-rays produced by $45^{\circ}$ Bragg diffraction was first reported by Champion and Whittem [4], where the topaz single crystal was used as a polarizer with a Philips PW 1520 wavelength dispersive spectrometer. Champion and Whittem said, "It is not too difficult with the Philips PW 1520 instruments to rotate the X-ray tube and sample holder about the axis of the collimator." This experiment was done before the era of solid state silicon X-ray detector.

After this experiment, Young et al. [5] reported a polarized XRF analysis using Barkla scattering with an energy dispersive $X$-ray detector though the details are not well known because the report of Young et al. was only the conference abstract, which was referred by Ryon [1]. Then, Dzubey et al. [6] and Howell et al. [7] reported the background reduction in XRF spectra using polarized X-rays produced by carbon and polyethylene scatterers respectively. Dzubey used a molybdenum anode X-ray tube at $45 \mathrm{kV}$. Howell employed a copper and silver anode tubes as X-ray sources operated at $40 \mathrm{kV}$. Ryon et al. [8, 9] developed a cylindrical polarizer made of light-element materials, e.g. $\mathrm{B}_{4} \mathrm{C}$. A plate made of $\mathrm{B}_{4} \mathrm{C}$ was curved around the side of a cylinder in order to gather X-rays emitted from an anode tube. By using the cylindrical polarizer, the X-ray intensity increased, which led to the improvement of the detection limit compared with the direct excitation. Kitov [10] theoretically derived the spectral function of the scattered radiation by a $B_{4} C$ polarizer, which elucidated the appropriate thickness of the polarizer in order to produce the highly polarized $\mathrm{X}$-rays when a molybdenum anode tube was used as an X-ray source. The simulation of the scattering efficiency of Barkla scatterers was reported by Swoboda et al. [11], in which $\mathrm{Al}_{2} \mathrm{O}_{3}$ was selected as a suitable polarizer for the analysis over a wide energy range. Revenko et al. [12] experimentally compared the scattering efficiency from metallic oxide and carbide polarizers, $\mathrm{Al}_{2} \mathrm{O}_{3}, \mathrm{TiB}_{4} \mathrm{C}$, $\mathrm{Ti}, \mathrm{TiO}_{2}, \mathrm{Y}_{2} \mathrm{O}_{3}$, and applied these scatterers to the determination of several elements concentrations in rock samples. In these previous papers [5-12], light elements were employed as Barkla scatterers in terms of the background reduction and the scattering efficiency.

The Bragg diffraction polarizer at $45^{\circ}$ is expected to produce $100 \%$ polarization. Using the Bragg diffraction, X-rays with particular wavelength can be produced. Aiginger et al. [13] used a single copper crystal for $\mathrm{Cu}$ $K a \mathrm{X}$-ray monochromator as a polarizer. The single copper crystal was cut along (113) plane $(2 d=2.18 \AA)$,

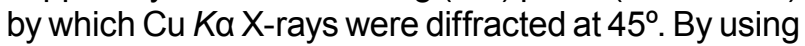
the polarized $X$-rays, elements below $Z=29$ could be excited. However, when the energy of monochromatic incident X-rays is less than absorption edges of elements in a sample, the polarized X-rays generated by the Bragg diffraction cannot excite such elements i.e. the polarization produced by the Bragg diffraction is not suited for the analysis of multiple unknown elements. The polarization by the means of $X$-ray scattering with light elements or various kinds of secondary targets can excite $X$-ray fluorescence without the limitation of the incident X-ray energy. Commercially available 3D-polarized XRF spectrometers appeared as Ametek Spectro XEPOS in 1999, Panalytical Epsilon 5 in 2003, and Rigaku NEXCG in 2008. These commercial spectrometers employ the secondary target method. In the case of Epsilon 5, for instance, the secondary targets can be attached to the spectrometer, according to quantified elements, e.g. 15 secondary targets including $\mathrm{Ca}, \mathrm{Fe}$, $\mathrm{Ge}, \mathrm{Zr}, \mathrm{Ag}, \mathrm{Mo}, \mathrm{BaF}_{2}, \mathrm{Al}_{2} \mathrm{O}_{3}$. The applied voltage to an $X$-ray tube can be set from 25 to $100 \mathrm{kV}$ [14]. In the case of using secondary targets, however, the polarization is far from perfect, which sometimes leads to the poor background reduction compared to using the Bragg diffraction method. Especially when using $L$ lines as an analytical line, they add complexity to the quantitative analysis in the polarized XRF [15].

Recently, Guerra et al. [16] and Pessanha et al. [17] reported a $50 \mathrm{~W}$ X-ray tube 3D-polarized XRF spectrometer. Encouraged by these low power polarized XRF spectrometers, we have assembled a polarized $\mathrm{XRF}$ spectrometer employing an acrylic polarizer as Barkla scatterer with a low-power X-ray tube which was operated with 25 and $40 \mathrm{~mW}$. Measured spectra of the stainless steel showed the decrease of the nickel $\mathrm{Ka}$ line $(7.5 \mathrm{keV})$ compared with those measured in a non- 
polarized geometry, though the measurement time set as the iron Ka peak maximum had the same intensity in both geometries. When the applied voltage was lower, the relative intensity of the continuum background originating from Bremsstrahlung and the tungsten $L \beta$ peak $(9.7$ $\mathrm{keV}$ ) was reduced in the $3 \mathrm{D}$ geometry. These spectral changes of the $\mathrm{Ni} K$ line and the continuum background in the polarized geometry were investigated based on the Schrödinger's wave picture of Compton scattering and the polarization measurements of scattered X-rays from light- and heavy-element polarizers, through which it was found that Compton scattering from the acrylic polarizer had the higher degree of polarization than elastically scattered X-rays, and this resulted in the spectral changes in measured spectra.

\section{SPECTROMETER DESCRIPTION AND EXPERIMENTAL DETAILS}

In Fig. 1, our assembled three-dimensional (3D) polarized XRF spectrometer is shown. Fig. 1(a) is the overview of the spectrometer. The spectrometer was $25 \mathrm{~cm}$ in length, had a width of $10 \mathrm{~cm}$, and a height of $10 \mathrm{~cm}$. The metallic object that had the shape of a disk was part of a polarizer holder. The drawing from CAD (computer-aided design software) is shown in Fig. 1(b). Photos of the top view and the backside of the spectrometer are also shown in Figs. 1(c) and (d). Fig. 2 shows the inside of an acrylic block around the sample holder. The X-ray tube to the scatterer distance was $10 \mathrm{~mm}$, and the sample to detector distance was again $10 \mathrm{~mm}$. The $X$-ray path was air inside the thick acrylic block. The sample was inserted from the bottom of the acrylic block. The X-rays were made incident on a polarizer at an angle of $45^{\circ}$, and they were again reflected on a sample at an angle of $45^{\circ}$. A low power $X$-ray tube was a Moxtek (Orem UT) Ultra-Lite Magnum, $50 \mathrm{kV}$ and $4 \mathrm{~W}$, with a tungsten target [18]. As a scatterer, an acrylic $\left(\left(\mathrm{C}_{5} \mathrm{H}_{2} \mathrm{O}_{8}\right)_{n}\right)$ plate was used because acrylic is composed of elements with low atomic numbers and considered to have large Compton scattering cross section. The area of the acrylic plate was $80 \mathrm{~mm}^{2}$, and the thickness was $30 \mathrm{~mm}$. The detector was an SDD (RES-Lab, Osaka) [19]. The area of the detector was $100 \mathrm{~mm}^{2}$. The silicon crystal thickness was $450 \mu \mathrm{m}$. The thickness of beryllium window was $8 \mu \mathrm{m}$. A Peltier device was cooled down to $-30^{\circ} \mathrm{C}$. Peaking time was set at $6 \mu$ s at which the energy resolution had the width of $133 \mathrm{eV}$ for Mn Ka line. In order to reduce X-rays directly coming from the $X$-ray tube and to accurately measure the $W L \beta$ line intensity, a lead collimator that had a $2 \mathrm{~mm}$ diameter hole was attached to the detector window. A stainless steel SUS 316L (ASTM 316L) was measured by the polarized spectrometer. Applied voltage and current were $25 \mathrm{kV}, 1 \mu \mathrm{A}(25 \mathrm{~mW})$ and 40 $\mathrm{kV}, 1 \mu \mathrm{A}(40 \mathrm{~mW})$. A non-polarized (2D) geometry in order to compare measured spectra with the polarized geometry is shown in Fig. 3. The angle among X-ray tube, sample, and the detector was set at $90^{\circ}$. The $X$-ray tube to the sample distance was $10 \mathrm{~mm}$, and the
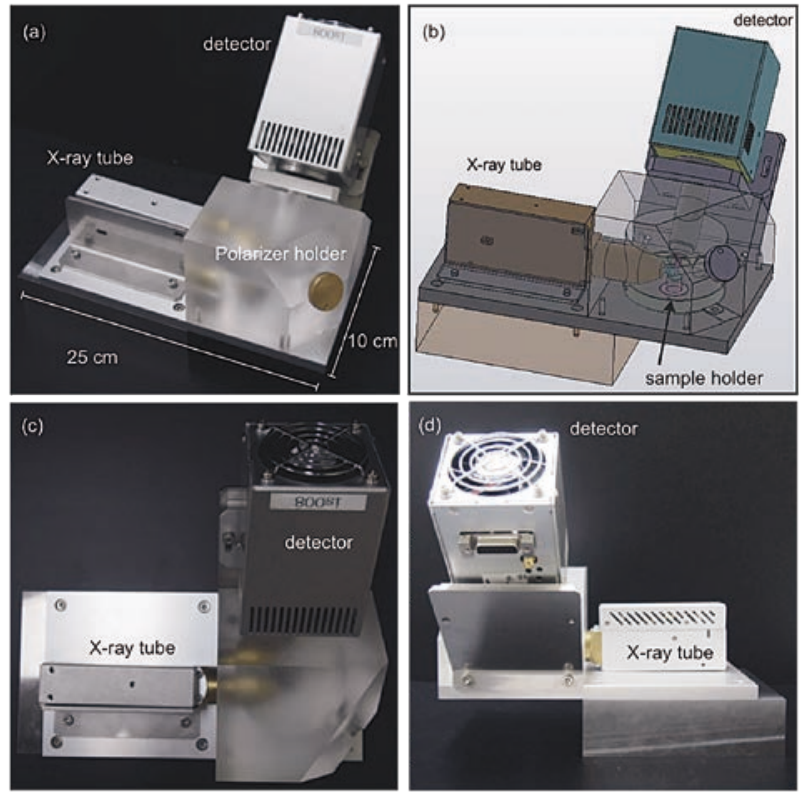

Fig. 1. Photos and drawing of our assembled polarized XRF spectrometer. (a) Overview of the spectrometer. The size of the spectrometer: length of $25 \mathrm{~cm}$, width of $10 \mathrm{~cm}$, and height of $10 \mathrm{~cm}$. The metallic object that appears to be a disc is a part of a polarizer holder. (b) Drawing by CAD. The sample holder can be inserted from the bottom of the acrylic block. (c) Top view and (d) backside of the spectrometer.

sample to detector distance was also $10 \mathrm{~mm}$. White arrows depicted in Fig. 3 indicate the X-ray path. In order to achieve the same number of counts on the $\mathrm{Fe} K a$, the dwelling time was changed according to the spectral intensity.

In order to evaluate the polarization of scattered $X$-rays from polarizers, a spectrometer for the polarization measurement was made. An X-ray tube, a polarizer, an analyzer, and a detector were arranged as shown in Fig. 4. The incident $X$-rays were first scattered on

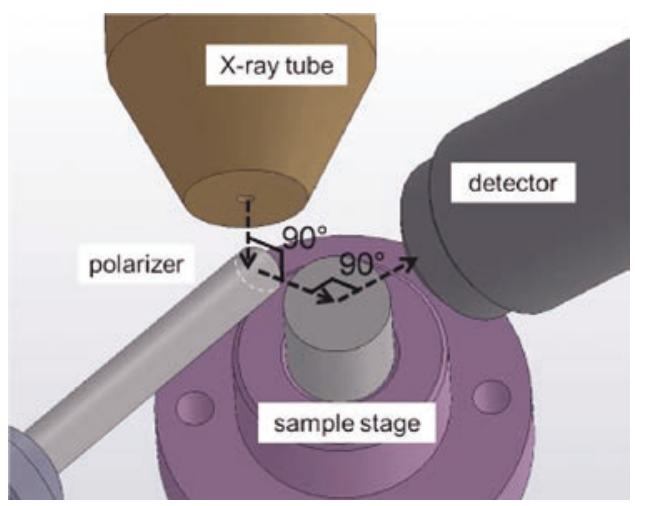

Fig. 2. Drawing around the sample stage. The angle among X-ray tube, polarizer and sample was $90^{\circ}$. The angle among polarizer, sample, and the detector was also $90^{\circ}$. The X-ray tube to polarizer distance was $10 \mathrm{~mm}$, and the sample to detector distance was again 10 $\mathrm{mm}$. The sample stage was made of brass. The polarizer was an acrylic rod. The X-ray path was air inside the thick acrylic block that is indicated as dotted arrows. 


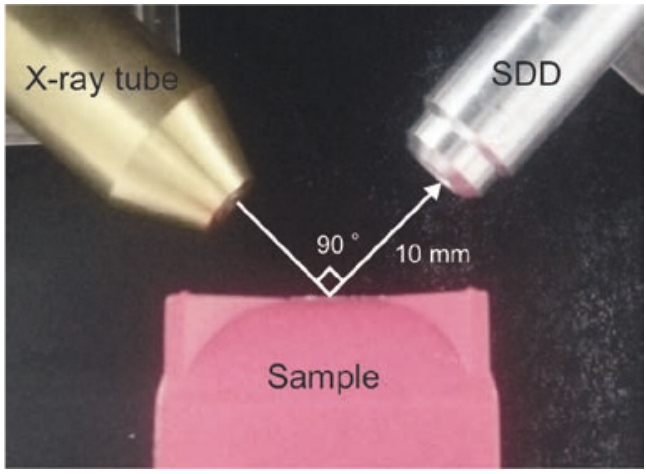

Fig. 3. Photo of the 2D geometry XRF configuration. The angle among $X$-ray tube, sample and detector was $90^{\circ}$. Each equipment distance was $10 \mathrm{~mm}$.

the polarizer at an angle of $45^{\circ}$, and then X-rays were again scattered in the direction of $45^{\circ}$ with the analyzer. With the use of a 3D printer, holders were made of a polylactic resin, which could change the detection angle $\theta$ by every $30^{\circ}$ in the $y-z$ plane in Fig. 4(a). $\theta$ was defined as the angle between the directions of the incident $X$-rays and the scattered $X$-rays from the analyzer. The intensity of scattered $X$-rays was measured changing the detection angle. The X-ray tube was the same one as the above, which was operated at $25 \mathrm{kV}$ and $20 \mu \mathrm{A}$. An acrylic and lead plates were used as polarizers, whose ratios of elastic and Compton scattering cross section were different as $1.6: 1.0$ of carbon and 33 : 1.0 of lead for $10-k e V$ photons [20]. An acrylic plate was employed as the scattering analyzer. Polarizers and the scattering analyzer could be attached to the $X$-ray tube holder and the detector holder. The degree of polarization of scattered X-rays was evaluated as the ratio of an amplitude of a modulation curve to the average of scattered X-ray intensity, $\frac{N_{/ /}-N_{\perp}}{N_{/ /}+N_{\perp}}$. Here, $N_{/ /}$and $N_{\perp}$ denote the intensity of scattered X-rays when

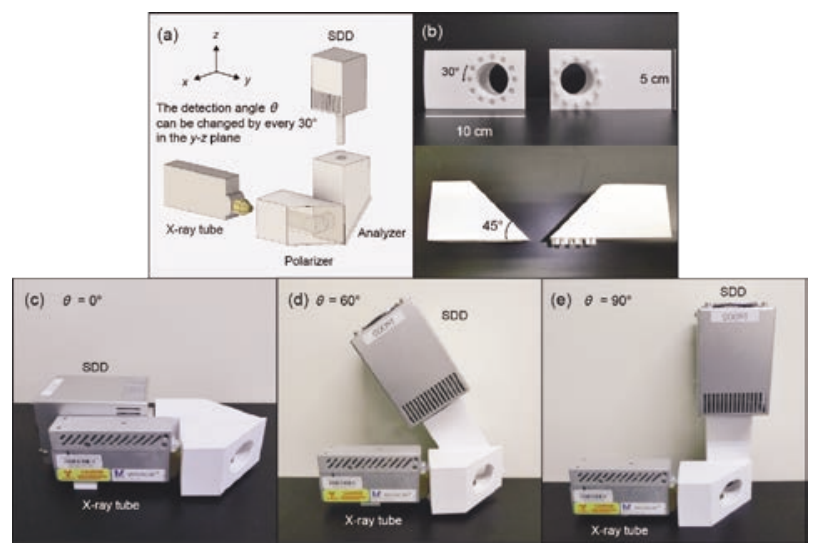

Fig. 4. 3D-printed spectrometer for the measurements of the $\mathrm{X}$-ray polarization. (a) Drawing of the spectrometer. (b) The X-ray tube holder and the detector holder. The detection angle $\theta$ could be changed by rotating the detector holder every $30^{\circ} . \theta=0^{\circ}, 60^{\circ}$, and $90^{\circ}$ are shown in (c), (d), and (e), respectively. The degree of polarization of scattered $\mathrm{X}$-rays were evaluated from the intensities when $\theta=0^{\circ}$ and $90^{\circ}$. the detection angle is parallel $\left(\theta=0^{\circ}\right.$ as shown in Fig. 4(c)) and perpendicular $\left(\theta=90^{\circ}\right.$ as shown in Fig. 4(e) to the direction of the incident $X$-rays.

\section{RESULTS and DISCUSSION}

Figures 5 and 6 show XRF spectra of stainless steel SUS 316L (ASTM 316L), the main components of which were $\mathrm{Fe}, \mathrm{Cr}(16 \%), \mathrm{Ni}(10 \%)$ and $\mathrm{Mo}(2 \%)$. $\mathrm{Pb}$ was originated from the X-ray collimator placed on the detector window. We compared spectra in the 3D geometry with those in the 2D geometry. Although the measuring time was changed in order to achieve the same number of counts on the Fe Ka, the measured spectra showed that the $\mathrm{Ni} K \alpha$ intensity decreased in the 3D geometry compared with that in the 2D geometry. This difference of $\mathrm{Ni} K a$ intensity between the 2D and $3 \mathrm{D}$ geometries was due to Compton scattering. The $\mathrm{W}$ La energy is $8.396 \mathrm{keV}$, and the $\mathrm{Ni} \underline{K} \alpha$ absorption edge is $8.330 \mathrm{keV}$. The difference is only $66 \mathrm{eV}$. The energy shift when the incident $X$-rays were Compton-scattered at an angle of $90^{\circ}$ is $136 \mathrm{eV}$. Thus, the energy of the scattered W L $\alpha$ line was shifted to the lower side, 8.260 $\mathrm{keV}$, which was less than the $\mathrm{Ni} K$ absorption edge. The Compton scattered W $L a$ line could not therefore excite $\mathrm{Ni} K$ line. Sasaki et al. [21] reported the intensity of Compton scattering lines when measuring spectra of an acrylic plate with a rhodium target X-ray tube was much higher than that of the elastic lines. Therefore, when employing low-atomic number materials as polarizers, Compton scattering effect on spectra is not negligible.

As is found from Fig. 5 ( $25 \mathrm{kV}$ tube potential), the relative intensity of the continuum background originating from Bremsstrahlung and the $W L \beta$ peaks from the $X$-ray tube was weaker in the $3 \mathrm{D}$ geometry compared with that in the 2D geometry in the energy range of from 7 to $15 \mathrm{keV}$. As shown in Fig. 6, on the other hand, the continuum background and the $W L \beta$ peaks had essentially the same intensity for both of the $3 D$ and 2D geometries when the X-ray tube voltage was $40 \mathrm{kV}$.

In order to consider the reason why the continuum background and the $W L \beta$ peak intensity were weaker

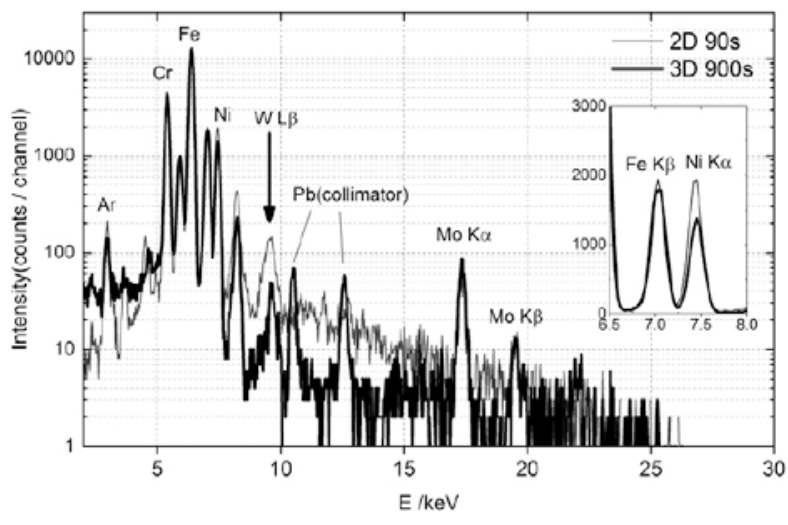

Fig. 5. Comparison of XRF spectra of ASTM 316L between $3 \mathrm{D}$ and $2 \mathrm{D}$ geometries, with the tube voltage of 25 $\mathrm{kV}$. The tube current was $1 \mu \mathrm{A}$. The same spectra in the energy range of $6.5-8.0 \mathrm{keV}$ are shown in the inset. 


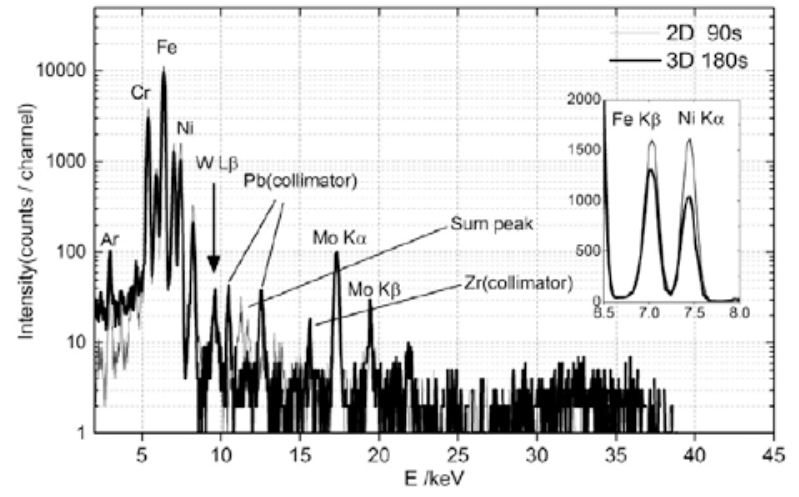

Fig. 6. XRF spectra of ASTM 316L. The tube voltage was $40 \mathrm{kV}$. Other conditions were similar to those of Fig. 4 . While the intensity of the $W \angle \beta$ peaks was different between $3 \mathrm{D}$ and 2D geometries when the applied voltage was $25 \mathrm{kV}$, they had the same intensity for both geometries.

in the $3 D$ geometry compared with the $2 D$ geometry when the lower voltage was applied to the X-ray tube, Compton scattering that occurred on the acrylic polarizer should be addressed. When the incident X-ray energy is $10 \mathrm{keV}(=\hbar \omega$ in Fig. 7), the Compton scattered X-ray energy by a free electron in the scatterer observed at $\theta=90^{\circ}$ is $200 \mathrm{eV}$ less $\left(=\hbar \omega-\hbar \omega^{\prime}\right)$. The shifted X-ray energy by $200 \mathrm{eV}$ is converted to the kinetic energy of the free electron, and thus the group velocity ( $u$ in Fig. 7) of the recoil electron is $8.2 \cdot 10^{6} \mathrm{~m} / \mathrm{s}$. The de Broglie wavelength $(\Lambda$ in Fig. 8$)$ of this electron can be estimated to be $0.1 \mathrm{~nm}(1 \AA)$. The wave velocity (phase velocity, $U)$ of the de Broglie wave is $p /(2 m)$, which is half of the group velocity $p / m$ and thus is $4.1 \cdot 10^{6} \mathrm{~m} / \mathrm{s}$. Here the momentum of electron $p$ is related to the de Broglie wavelength $\Lambda$ as $\Lambda=h / p$. The de Broglie wave is the periodic electron density, in other words, a periodic lattice, moving with the phase velocity depicted in Fig. 8. The incident X-rays are, therefore, Braggdiffracted by the moving periodic lattice, and thus the diffracted X-ray wavelength is Doppler-shifted to the longer wavelength, expressed by $200 \mathrm{eV}$ less photon energy. The length of a wave train associated with one

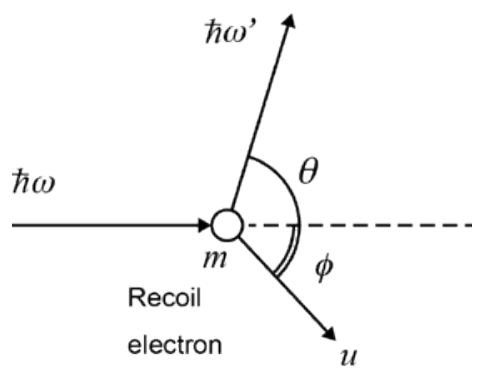

Fig. 7. Particle picture of Compton scattering. The dotted circle on the center represents an electron. $m$ denotes the mass of the electron. The incident $X$-rays are scattered from the electron at the angle of $\theta$, and their energies $\hbar \omega$ are shifted to $\hbar \omega$ '. The recoil electron moves to the direction of $\varphi$ against the incident $X$-rays with group velocity $u$.

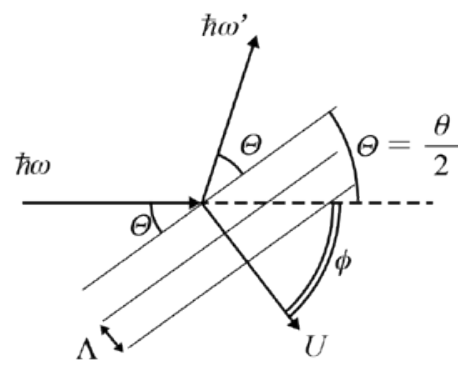

The de Broglie wave of

the recoil electron

Fig. 8. Schrödinger's wave picture of Compton scattering. The de Broglie wave of the recoil electron can be regarded as a Bragg crystal going away with phase velocity $U$. The de Broglie wavelength $\Lambda$ corresponds to lattice spacing, which varies with respect to the incident X-ray energy. By the moving de Broglie wave, the incident $X$-rays are Bragg-diffracted at the angle of $\Theta$ and Doppler-shifted to the longer wavelength.

electron moving with a kinetic energy of $200 \mathrm{eV}$ is said to be ten nanometers. The wavelength of the electron density wave can be inversely regarded as a lattice constant, and the incident $X$-rays are diffracted by the de Broglie wave of the recoil electron going away from the X-rays with the phase velocity of about one percent of the light speed. This is the Schrödinger's picture of Compton scattering [22-25].

When the incident X-ray energies were 1, 10, 15,25 , and $40 \mathrm{keV}$, phase velocity, the de Broglie wavelength, and the scattering angle of the recoil electron were calculated as shown in Table. Each de Broglie wavelength of the recoil electron and phase velocity depended on the incident X-ray energies. On the other hand, the scattering angle kept almost $45^{\circ}$. Combined with the wave picture of Compton scattering, the de Broglie wave of the recoil electron in the polarizer can be regarded as a Bragg crystal that is moving to the direction of a particular angle, of which moving direction becomes much closer to the angle of $45^{\circ}$ when the incident X-ray energy becomes lower. Namely, the de

Table IncidentX-ray energy dependence on phase velocity, de Broglie wavelength, and scattering angle of the recoil electron. The de Broglie wave moves to the direction of $45^{\circ}$ with about one percent of light speed, with changing its wavelength. Light speed is $3.0 \cdot 10^{8} \mathrm{~m} / \mathrm{s}$

\begin{tabular}{c|c|c|c}
\hline $\begin{array}{c}\text { Incident } \\
\text { X-ray } \\
\text { energy } \\
(\mathrm{keV})\end{array}$ & $\begin{array}{c}\text { Phase } \\
\text { velocity, } U \\
(\text { Light speed } \\
\text { units })\end{array}$ & $\begin{array}{c}\text { de Broglie } \\
\text { wavelength } \\
\text { of the recoil } \\
\text { electron, } \Lambda \\
(\AA)\end{array}$ & $\begin{array}{c}\text { Scattering } \\
\text { angle, } \varphi\end{array}$ \\
\hline 1 & $1.4 \cdot 10^{-3}$ & 8.8 & $44.9^{\circ}$ \\
\hline 10 & $1.4 \cdot 10^{-2}$ & 0.9 & $44.4^{\circ}$ \\
\hline 15 & $2.0 \cdot 10^{-2}$ & 0.6 & $44.2^{\circ}$ \\
\hline 25 & $3.4 \cdot 10^{-2}$ & 0.4 & $43.6^{\circ}$ \\
\hline 40 & $5.3 \cdot 10^{-2}$ & 0.2 & $42.8^{\circ}$ \\
\hline
\end{tabular}




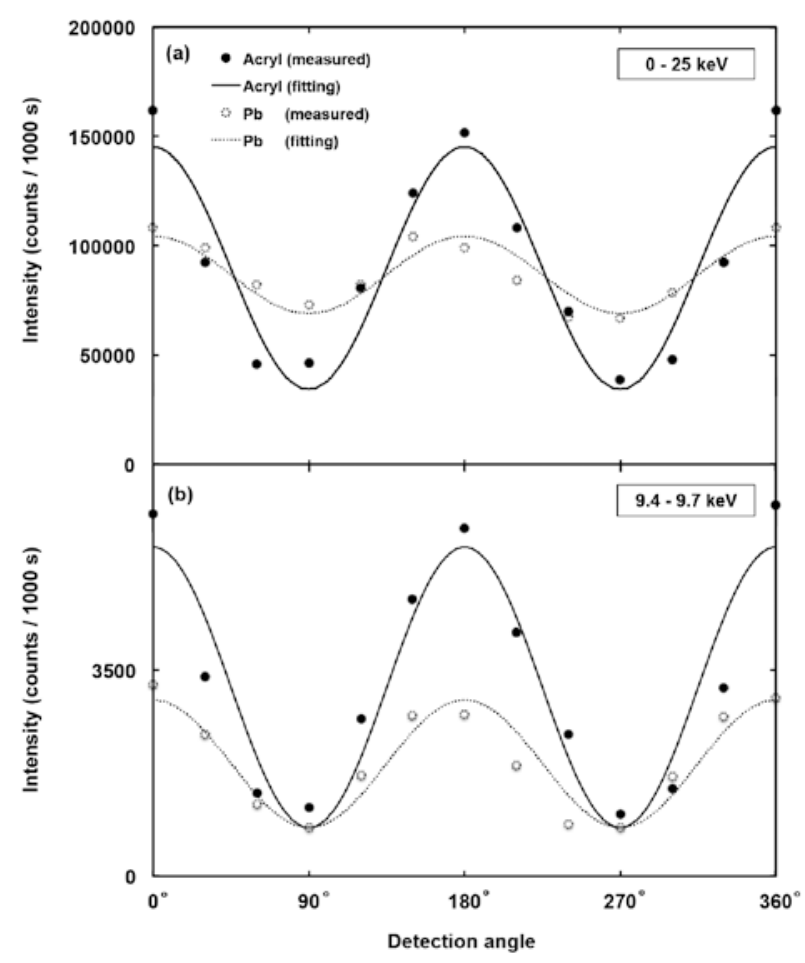

Fig. 9. The angular dependence of the integrated intensities of scattered X-rays in the energy range of (a) 0 to 25 keV and (b) 9.4 to $9.7 \mathrm{keV}$. Solid dots (measured) and lines (fitted) are for acryl, and broken ones are for $\mathrm{Pb}$.

Broglie wavelength of the recoil electron corresponds to the lattice spacing that changes itself with the incident $X$-ray energy so as to diffract $X$-rays at the angle of $45^{\circ}$ for any wavelength of the incident $X$-rays. As $45^{\circ}$ Bragg diffraction can theoretically produce the perfect polarized X-rays, polarizers made of light elements which have a large Compton scattering cross section is able to make the incident X-rays highly polarizable over a wide energy range.

In order to experimentally prove that Compton scattered X-rays were more highly polarized than elastically scattered $X$-rays, the degree of polarization of scattered X-rays by the acrylic and lead plates were measured. Fig. 9 shows the angular dependence of the integrated intensity of scattered X-rays within the energy range of 0 to $25 \mathrm{keV}$ (Fig. 9(a)) and 9.4 to $9.7 \mathrm{keV}$ (Fig. 9(b)). In the energy range of 0 to $25 \mathrm{keV}$, the degree of polarization was 0.6 when using the acrylic plate as a polarizer, which was three times of that in the case of using the lead plate. Next, we focus on the scattered X-ray intensity in the energy range of 9.4 to $9.7 \mathrm{keV}$. For $10-\mathrm{keV}$ photons, the ratio of the elastic scattering cross section to Compton scattering one is 1.6: 1.0 for carbon [19]. The acrylic plate was mainly composed of carbon, thus, scattered X-rays from the acrylic plate were the mixture of the elastic and Compton scattering in this energy range. On the other hand, in the case of using the lead plate, the Compton scattering cross section was one hundredth of the elastic scattering cross section, which meant that scattering X-rays from the lead plate were only the elastically scattered X-rays.
Estimated degrees of polarization were 0.74 and 0.58 when using the acrylic and lead plates respectively. This result of the polarization measurements showed that the acrylic polarizer composed of light elements of which Compton scattering cross section was large could produce polarized X-rays with the higher degree of polarization than the lead plate. Previous papers related to Barkla scattering polarization [5-12] employed light-element polarizers, in which the large background reduction was achieved because the inelastic Compton scattered $\mathrm{X}$-rays were used as excitation sources rather than the elastic scattering.

In the present study, the $W L \alpha$ and $L \beta$ lines from the $X$-ray tube were not only elastically but also inelastically scattered. The energy difference between elastic and inelastic scattering is difficult to be experimentally discriminated according to the resolution of the X-ray detector used, and we sometimes regard them as the elastically scattered characteristic lines from the X-ray tube. However, truly, the majority is the inelastic Compton scattering, especially when a polarizer made of lightelement materials is employed. When using the incident X-rays with lower energy, the scattering angle of the electron becomes close to $45^{\circ}$. Therefore, Compton scattered $X$-rays from the acrylic scatterer were highly polarized when the applied voltage was $25 \mathrm{kV}$, which led to the reduction of the spectral background and the $\mathrm{W} L$ lines.

\section{CONCLUSIONS}

We assembled the low-power 3D-polarized XRF spectrometer with the acrylic polarizer and compared measured spectra of the stainless steel between the $3 \mathrm{D}$ and 2D geometries. The measured spectra showed that the Ni Ka intensity decreased, which was because the energy of the W La line was Compton-shifted to the lower energy side than the $\mathrm{Ni} K$ absorption edge. When the lower voltage was applied to the X-ray tube in the 3D geometry, the spectral background and the $W L \beta$ peak from the X-ray tube were reduced. Based on Schrödinger wave picture of the Compton scattering, the de Broglie wave can be regarded as Bragg crystal that changes its lattice spacing so that it always diffracts $X$-rays in the direction of $45^{\circ}$. When X-rays diffracted by $45^{\circ}$ Bragg diffraction were observed at $\theta=90^{\circ}$, they theoretically had $100 \%$ polarization. When the applied voltage to the X-ray tube was lower, the scattering angle of the recoil electron became close to $45^{\circ}$, which corresponded to $45^{\circ}$ Bragg diffraction. Thus, Compton scattered X-rays were considered to be highly polarized. The polarization measurements of scattered X-rays showed that X-rays scattered on the acrylic plate had the high degree of polarization. We have revealed that Compton scattering from the polarizer that was made of light elements resulted in the reduction of the background and the intensity changes of characteristic $X$-rays in the spectra measured by using the low-power polarized XRF spectrometer. 


\section{ЛИТЕРАТУРА}

1. Ryon R.W. Polarization for background reduction in EDXRF - The technique that does indeed work //Advances in X-Ray Analysis. 2003. V. 46. P. 352-362.

2. Barkla C.G. Polarized Röntgen radiation // Philosophical Transactions of the Royal Society of London. Series A, Containing Papers of a Mathematical or Physical Character. 1905. V. 204. P. 467-479.

3. Standzenieks P., Lindgren E.S. Background reduction of $X$-ray fluorescence spectra in a secondary target energy dispersive spectrometer // Nuclear Instruments and Methods. 1979. V. 165. P. 63-65.

4. Champion K.P., Whittem R.N. Utilization of increased sensitivity of X-ray fluorescence spectrometry due to polarization of the background radiation // Nature. 1963. V. 199, № 4898. P. 1082. 5. Young J.C., Vane R.A., Lenehan J. P. Background reduction by polarization in energy dispersive X-ray spectrometry // Western Regional Meeting of the American Chemical Society, San Diego, October 1973.

6. Dzubey T.G., Jarrett B.V., Jaklevic J. M. Background reduction in X-ray fluorescence spectra using polarization // Nuclear Instruments and Methods. 1973. V. 115, № 1. P. 297-299.

7. Howell R.H., Pickles W.L., Cate jr. J.L. X-Ray Fluorescence Experiments with Polarized X-Rays // Advances in X-Ray Analysis. vol. 17 (Proceedings of the Twenty-Second Annual Conference on Applications of X-Ray Analysis held in Denver, August 22-24, 1973), 1974. P. 265- 277.

8. Ryon R.W. Polarized radiation produced by scatter for energy dispersive $\mathrm{x}$-ray fluorescence trace analysis // Advances in X-Ray Analysis. 1977. V. 20. P. 575-590.

9. Ryon R.W., Zahrt J.D. Improved x-ray fluorescence capabilities by excitation with high intensity polarized x-rays, UCRL, 1978, 80937. Jul 1978; 15 p; 27 Conference on applications of x-ray analysis; Denver, CO, USA; 1 - 4 Aug 1978; CONF-780822-2; [Электронный ресурс]: https://inis.iaea.org/search/search. aspx?orig_q=RN:10443911 (дата обращения 13 июня 2018 г.) 10. Kitov B.I. Spectrum function of polarizer-scattered x-ray tube radiation // X-ray spectrometry. 2005. V. 34. P. 52-55. 11. Swoboda W., Beckhoff B., Kanngieber B., Scheer J. Use of $\mathrm{Al}_{2} \mathrm{O}_{3}$ as a Barkla scatterer for the production of polarized excitation radiation in EDXRF // X-ray Spectrometry. 1993. V. 22. P. 317-322.

12. Ревенко А.Г, Ревенко В.А., Худоногова Е.В., Жалсараев Б.Ж. Рентгенофлуоресцентное определение Rb, Sr, Y, Zr, Nb, $\mathrm{Sn}, \mathrm{Ba}, \mathrm{La}, \mathrm{Ce}$ в горных породах на энерго-дисперсионном спектрометре с пол-яризатором // Аналитика и контроль. 2002, T. 6, №. 4. C. 400-407.

13. Panalytical: Epsilon-5 [Электронный pecypc]: http://www. speciation.net/Database/Instruments/PANalytical-BV/Epsilon5-;i1663] (дата обращения 13 июня 2018 г.)

14. Aiginger H., Wobrauschek P., Brauner C. Energy-dispersive fluorescence analysis using Bragg-reflected polarized X-rays // Nuclear Instruments and Methods. 1974. V. 120, № 3. P. 541-542.

15. Tanaka. R., Akiba S., Kawai. J. X-Ray Fluorescence Intensity Using Polarization // Adv. X-Ray. Chem. Anal., Japan. 2017. V. 48. P. 352-356.

16. Guerra M., Alves M., Carvalho M. L. and Pessanha S. Development of a portable EDXRF spectrometer with a secondary target in a tri-axial geometry // EXRS2016. Gothenburg. June 2016.

17. Pessanha S., Alves M., Sampaio J. M., Santos J. P., Carvalho M.L., Guerra M. A novel portable energy dispersive X-ray fluorescence spectrometer with triaxial geometry // Journal of Instruments. 2017. № 12. P. 01014-01027.
18. Moxtek. X-ray Components [Электронный ресурc]: http:// moxtek.com/x-ray-products (дата обращения 13 июня 2018 г.). 19. RES-Lab. [Электронный ресурc]: http://www.res-lab. com (дата обращения 13 июня 2018 г.).

20. Hubbel J. H..Photon Cross-Sections, Attenuation Coefficients and Energy Absorption Coefficients from $10 \mathrm{keV}$ to $100 \mathrm{GeV}$, National Bureau of Standards, 1969. 92 р. [Электронный pecypc]: http://nvlpubs.nist.gov/nistpubs/Legacy/NSRDS/ nbsnsrds29.pdf (дата обращения 13 июня 2018 г.).

21. Sasaki N., Okada K., Kawai J. X-ray tube spectral measurement method for quantitative analysis of X-ray fluorescence analysis // X-ray spectrometry. 2010. V. 39, №. 5. P. 328-331.

22. Schrödinger E. Über den Comptoneffekt // Annalen der Physik. 1927. V. 82. P. 257-264.

23. Landé A. Quantum Mechanics. New York, Pitman Publishing Corporation, 1951. P. 15-18.

24. Kawai J. Quantum Spectrochemistry, $2^{\text {nd }}$ Ed. Tokyo: AGNE Gijutu Center, 2015, P. 10-23.

25. Tanaka. R., Kawai. J. Polarizer for Continuous White X-Rays Using The de Broglie Wave of $45^{\circ}$-Recoil Electron via Compton Scattering // Adv. X-Ray. Chem. Anal. Japan. 2018. V. 49. P. 189-194.

\section{REFERENCES}

1. Ryon R.W. Polarization for background reduction in EDXRF - The technique that does indeed work, Advances in X-Ray Analysis, 2003, vol. 46, pp. 352-362.

2. Barkla C.G. Polarized Röntgen radiation, Philosophical Transactions of the Royal Society of London. Series A, Containing Papers of a Mathematical or Physical Character, 1905, vol. 204, pp. 467-479.

3. Standzenieks P., Lindgren E.S. Background reduction of $X$-ray fluorescence spectra in a secondary target energy dispersive spectrometer, Nuclear Instruments and Methods, 1979, vol. 165, pp. 63-65.

4. Champion K.P., Whittem R.N. Utilization of increased sensitivity of X-ray fluorescence spectrometry due to polarization of the background radiation, Nature, 1963, vol. 199, no. 4898, p. 1082. doi:10.1038/1991082a0

5. Young J.C., Vane R.A., Lenehan J.P. Background reduction by polarization in energy dispersive X-ray spectrometry, Western Regional Meeting of the American Chemical Society, San Diego, October 1973.

6. Dzubey T.G., Jarrett B.V., Jaklevic J.M. Background reduction in X-ray fluorescence spectra using polarization, Nuclear Instruments and Methods, 1973, vol. 115, no. 1, pp. 297-299. 7. Howell R.H., Pickles W.L., Cate jr. J.L. X-Ray Fluorescence Experiments with Polarized X-Rays, Advances in X-Ray Analysis, vol. 17 (Proceedings of the Twenty-Second Annual Conference on Applications of X-Ray Analysis held in Denver, August 22-24, 1973), 1974, pp. 265-277.

8. Ryon R.W. Polarized radiation produced by scatter for energy dispersive x-ray fluorescence trace analysis, Advances in X-Ray Analysis, 1977, vol. 20, pp. 575-590.

9. Ryon R.W., Zahrt J.D. Improved $x$-ray fluorescence capabilities by excitation with high intensity polarized x-rays, UCRL, 1978, 80937. Jul 1978; 15 p. 27 Conference on applications of $x$-ray analysis; Denver, CO, USA; 1-4 Aug 1978; CONF-780822-2. Available at: https://inis.iaea.org/search/search.aspx?orig_ q=RN:10443911 (accessed 13 June 2018).

10. Kitov B.I. Spectrum function of polarizer-scattered x-ray tube radiation, X-ray spectrometry, 2005, vol. 34, pp. 52-55. 11. Swoboda W., Beckhoff B., Kanngieber B., Scheer J. Use of $\mathrm{Al}_{2} \mathrm{O}_{3}$ as a Barkla scatterer for the production of polarized 
excitation radiation in EDXRF, X-ray Spectrometry, 1993, vol. 22, pp. 317-322.

12. Revenko A. G., Revenko V. A., Khudonogov E.V., Zhalsaraev B. [X-ray fluorescent determination of Rb, $\mathrm{Sr}, \mathrm{Y}, \mathrm{Zr}, \mathrm{Nb}, \mathrm{Sn}$, $\mathrm{Ba}, \mathrm{La}$, and $\mathrm{Ce}$ in rocks on an energy dispersion spectrometer with a polarizer], Analitika i Kontrol` (Analytics and Control), 2002, vol. 6, no. 4, pp. 400-407 (in Russian).

13. Panalytical: Epsilon-5. Available at: http://www.speciation. net/Database/Instruments/PANalytical-BV/Epsilon-5-;i1663 (accessed 13 June 2018).

14. Aiginger H., Wobrauschek P., Brauner C. Energy-dispersive fluorescence analysis using Bragg-reflected polarized X-rays, Nuclear Instruments and Methods, 1974, vol. 120, no. 3, pp. 541-542.

15. Tanaka. R., Akiba S., Kawai. J. X-Ray Fluorescence Intensity Using Polarization, Adv. X-Ray. Chem. Anal., Japan, 2017, vol. 48, pp. 352-356.

16. Guerra M., Alves M., Carvalho M. L., Pessanha S. Development of a portable EDXRF spectrometer with a secondary target in a tri-axial geometry, EXRS2016, Gothenburg, June 2016. 17. Pessanha S., Alves M., Sampaio J. M., Santos J. P., Carvalho M.L., Guerra M. A novel portable energy dispersive X-ray fluorescence spectrometer with triaxial geometry, Journal of Instruments, 2017, no. 12, pp. 01014-01027. doi: 10.1088/17480221/12/01/P01014.
18. Moxtek. X-ray Components. Available at: http://moxtek. com/x-ray-products (accessed 13 June 2018)

19. RES-Lab. Available at: http://www.res-lab.com (accessed 13 June 2018).

20. Hubbel J.H. Photon Cross-Sections, Attenuation Coefficients and Energy Absorption Coefficients from $10 \mathrm{keV}$ to $100 \mathrm{GeV}$, National Bureau of Standards, 1969, 92 p. Available at: http:// nvlpubs.nist.gov/nistpubs/Legacy/NSRDS/nbsnsrds29.pdf (accessed 13 June 2018).

21. Sasaki N., Okada K. and Kawai J. // X-ray tube spectral measurement method for quantitative analysis of X-ray fluorescence analysis, X-ray spectrometry, 2010, vol. 39, no. 5, pp. 328-331. doi: 10.1002/xrs.1271

22. Schrödinger E. // Über den Comptoneffekt, Annalen der Physik, 1927, vol. 82, pp. 257-264.

23. Landé A. Quantum Mechanics, New York, Pitman Publishing Corporation, 1951, pp. 15-18.

24. Kawai J. Quantum Spectrochemistry, 2008, 2015 - $2^{\text {nd }}$ Ed., AGNE Gijutu Center, Tokyo, pp.10-23.

25. Tanaka. R. , Kawai. J. Polarizer for Continuous White $X$-Rays Using The de Broglie Wave of $45^{\circ}$-Recoil Electron via Compton Scattering, Adv. X-Ray. Chem. Anal., Japan, 2018, vol. 49, pp.189-194. 